\title{
Dopamine and Serotonin Transporter Availability During Acute Alcohol Withdrawal: Effects of Comorbid Tobacco Smoking
}

\author{
Kelly P Cosgrove*,1,2, Erica Krantzler ${ }^{1,2}$, Erin B Frohlich ${ }^{1,2}$, Stephanie Stiklus',2, Brian Pittman', \\ Gilles D Tamagnan ${ }^{1,3}$, Ronald M Baldwin ${ }^{1,2}$, Frederic Bois ${ }^{1,2}$, John P Seibyl ${ }^{1,3}$, John H Krystal ${ }^{1,2}$, \\ Stephanie S O'Malley' and Julie K Staley ${ }^{1,2}$
}

'Department of Psychiatry, Yale University School of Medicine, New Haven, CT, USA; ${ }^{2}$ VA Connecticut Healthcare System, West Haven, CT, USA;

3 Institute for Neurodegenerative Disorders, New Haven, CT, USA

\begin{abstract}
Tobacco smoking is highly comorbid with heavy alcohol drinking, yet the interaction of tobacco smoking and alcohol drinking on brain catecholaminergic synaptic markers is unexplored. Here we evaluate the effects of alcohol drinking alone from comorbid alcohol drinking and tobacco smoking on dopamine (DA) and serotonin (5-HT) transporter availability. A total of 14 heavy alcohol drinking smokers $(n=6)$ and nonsmokers $(n=8)$ and 14 age-matched control smokers $(n=6)$ and nonsmokers $(n=8)$ were imaged with $\left[{ }^{123}\right] \beta$-CIT single photon emission computed tomography. Alcohol drinking smokers and nonsmokers consumed I $34.3 \pm 100.3$ and $196.5 \pm$ I 39.9 drinks, respectively, over the previous month and were imaged during acute withdrawal, eg within 5 days of their last drink. Striatal DA transporter availability was significantly higher $(16 \%, P=0.04)$ in alcohol drinkers compared to controls. 5-HT transporter availability was also significantly higher in alcohol drinkers vs controls in the brainstem $(25 \%, P=0.00 \mathrm{I})$ and the diencephalon $(8 \%, P=0.0 \mathrm{I})$. This elevation was restricted to alcohol drinking nonsmokers with higher DA transporter availability in the striatum $(26 \%, P=0.006)$, and higher 5 -HT transporter availability in the diencephalon $(26 \%, P=0.04)$ and brainstem $(42 \%, P<0.0002)$. There was a significant positive correlation between days since last drink and $5-\mathrm{HT}$ transporter availability in the diencephalon $(r=0.60, P=0.023)$ and brainstem $(r=0.54, P=0.047)$, in the total group of alcohol drinkers and in the nonsmokers, but not the smokers. During the first week of abstinence, DA and 5-HT transporter availability is higher in alcohol drinking nonsmokers but not in alcohol drinking smokers. Smoking appears to suppress neuroadaptive changes in DA and 5-HT transporters during acute withdrawal from alcohol. Neuropsychopharmacology (2009) 34, 22 18-2226; doi:I0. I038/npp.2009.49; published online I 3 May 2009
\end{abstract}

Keywords: dopamine; serotonin; alcohol withdrawal; tobacco smoking; SPECT; $\beta$-CIT

\section{INTRODUCTION}

Heavy alcohol drinking and tobacco smoking are highly associated. In the general population, it is estimated that $23 \%$ of people smoke cigarettes, up to $50 \%$ of individuals with alcohol abuse or dependence smoke (Grant et al, 2004), and as many as $30 \%$ of smokers are also alcohol dependent (Miller and Gold, 1998). Daily and occasional smokers are more likely than never smokers to be hazardous drinkers or to meet criteria for an alcohol use diagnosis (McKee et al, 2007). Smokers consume twice as much alcohol as nonsmokers (Carmody et al, 1985) and alcohol drinkers

*Correspondence: Dr KP Cosgrove, Department of Psychiatry, Yale University School of Medicine and the VA Connecticut Healthcare System, I 16A6, 950 Campbell Avenue, West Haven, CT 065 I 6, USA, Tel: + I 2039325711 ext. 3329, Fax: + I 2039373897 , E-mail: kelly.cosgrove@yale.edu

Received 17 September 2008; revised 20 March 2009; accepted 23 March 2009 who also smoke use more cigarettes per day than nonalcohol-dependent smokers (Dawson, 2000). The high comorbidity of smoking and drinking (Funk et al, 2006; Meyerhoff et al, 2006) may be due to several factors. First, social/peer pressures and availability of alcohol and cigarettes provide an environment that is conducive to drinking and smoking. Second, the effects of the drugs when used together may be additive or synergistic with regard to the reinforcing properties. Third, pharmacological effects or interactions of the drugs, such as changes in metabolism or cross-tolerance, may facilitate co-abuse. Fourth, genetic factors may contribute to this comorbidity. We hypothesize that in addition to these factors, there is an interaction of alcohol and tobacco smoking at the level of the dopamine (DA) and serotonin (5-HT) transporters.

A wealth of preclinical and clinical literature demonstrates the effects of both acute and chronic alcohol administration on the monoaminergic system (for reviews see Chastain, 2006; Vengeliene et al, 2008). Specifically, the 
mesolimbic DA system is the primary basis for the rewarding properties of most drugs of abuse, including alcohol (Di Chiara and Imperato, 1988). Although nicotine, the primary addictive chemical in tobacco smoke, exerts its initial effects at the nicotinic acetylcholine receptor, its effects on the mesolimbic DA system are also well documented (Janhunen and Ahtee, 2007). The serotonergic system is also implicated in both alcohol dependence (Vengeliene et al, 2008) and tobacco smoking (Seth et al, 2002). Dysfunctional 5-HT (Heinz et al, 2001) and DA system activity (Tupala and Tiihonen, 2004) may represent a vulnerability to alcohol dependence.

DA and 5-HT transporter availability has been examined in vivo in alcohol drinkers. Chronic alcohol consumption has been found to result in lower (Laine et al, 1999; Mash et al, 1996; Repo et al, 1999; Tupala et al, 2001), higher (Mash et al, 1996; Tiihonen et al, 1995), or unchanged (Volkow et al, 1996) availability of DA transporters compared to control subjects. Specifically, chronic alcohol consumption is associated with lower DA transporter availability in human alcohol drinkers who were imaged up to 4 weeks after their last drink compared to control subjects. Interestingly, this lower DA transporter availability increases during acute withdrawal, eg during the first 5 days of abstinence in humans (Laine et al, 1999) and at $24 \mathrm{~h}$ of abstinence in nonhuman primates (Mash et al, 1996).

5-HT transporter availability has been reported to be lower (Heinz et al, 1998b; Szabo et al, 2004) and similar (Brown et al, 2007) in recent and long-term abstinent alcoholics compared to controls. In nonhuman primates, higher brainstem 5-HT transporters were associated with reduced sensitivity to alcohol intoxication, which is a marker of vulnerability to develop alcohol dependence (Heinz et al, 1998a), and brainstem 5-HT transporter availability was positively correlated with amount of alcohol consumption (Heinz et al, 2003). Taken together, these associated lines of research suggest an initial reduction in DA and 5-HT transporter availability during acute withdrawal, which increases over time in alcohol-dependent subjects compared to healthy subjects. Importantly, despite the high comorbidity of tobacco smoking with alcoholism, the majority of these studies have not controlled for smoking status.

The development and validation of $\left[{ }^{123}\right] \beta$-CIT $(2 \beta$ carbomethoxy-3 $\beta$-(4-iodophenyl)tropane) for use with single photon emission computed tomography (SPECT) has allowed the simultaneous examination of DA and 5-HT transporter availability in a region-dependent manner (Seibyl et al, 1996, 1997). Here, we used $\left.{ }^{123}\right] \beta$-CIT SPECT to delineate the interactions of alcohol and comorbid alcohol and tobacco smoking on DA and 5-HT transporter availability during acute alcohol withdrawal ( $<1$ week).

\section{MATERIALS AND METHODS}

\section{Subjects}

A total of 14 heavy alcohol drinkers $(35.0 \pm 12.0$ years; age range 21-54; 5 women, 9 men; 1 Hispanic, 4 African American, 9 Caucasian) and 14 healthy controls ( $38.3 \pm 10.0$ years; age range 21-54; 7 women, 7 men; 2 African American, 12 Caucasian) participated in the study. In each group there were eight nonsmokers and six smokers (Table 1). For simplicity we refer to the groups as alcohol smokers, alcohol nonsmokers, control smokers, and control nonsmokers throughout the paper. A negative breathalyzer reading was required before initiating the intake appointment or brain imaging scans. Eligibility was determined as follows. Alcohol drinkers consumed at least 25 drinks per month based on self-report obtained using the Timeline FollowBack Interview (Sobell and Sobell, 1993). Control subjects, eg nondrinkers, were required to drink less than 10 drinks per year and could not have a history of alcohol abuse or dependence. Smoking status was verified by plasma cotinine levels $\geqslant 150 \mathrm{ng} / \mathrm{ml}$ on the day of intake. Nonsmokers were required to have smoked less than 100 cigarettes in their lifetime and none in the previous 2 years, with plasma cotinine levels $\leqslant 50 \mathrm{ng} / \mathrm{ml}$ on the day of intake. In addition, all subjects had a medical examination by a study physician to exclude any major medical issues or neurological disorders. This included a physical examination, electrocardiogram, serum chemistries, thyroid

Table I Demographics and Clinical Characteristics of Control and Alcohol Drinker Nonsmokers and Smokers

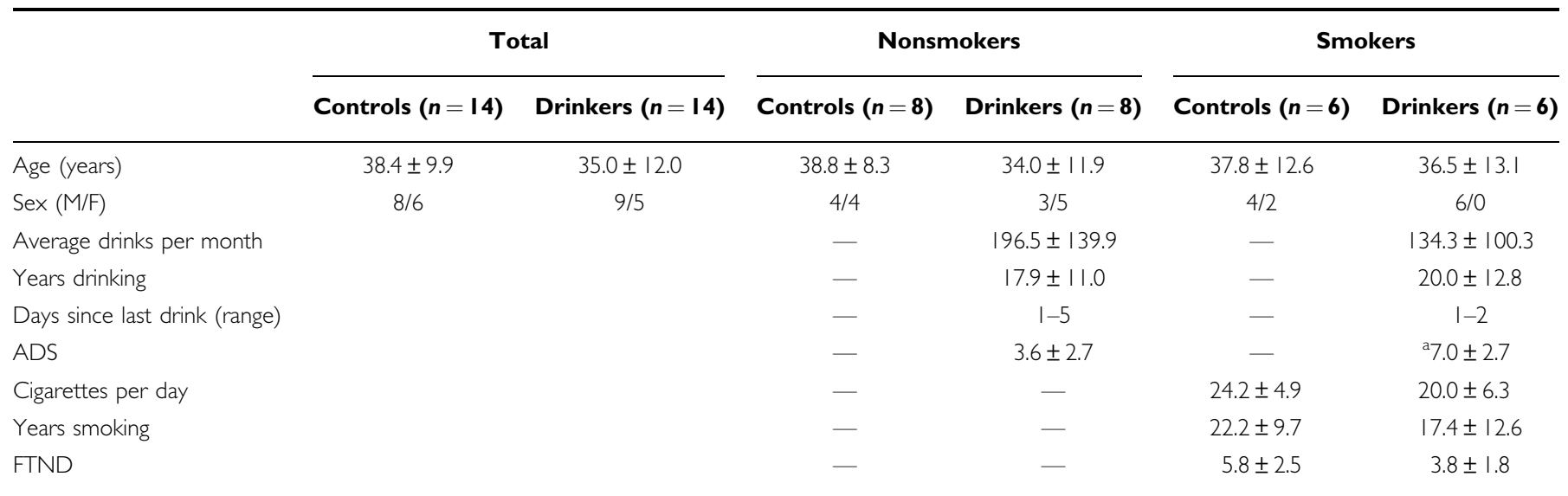

Data presented are means \pm standard deviation unless otherwise noted. There are no significant differences in any of the variables between groups. The CIWA-Ar was also given to all heavy alcohol drinking subjects on scan days. The scores were not elevated, and ranged from 0 to I, thus are not shown.

anformation only obtained for 3 of the 6 subjects. 
function studies, complete blood count, urinalysis, and urine toxicology screening. Subjects were given structured interviews using the SCID to rule out any Axis I disorder except alcohol abuse or dependence or nicotine dependence. All subjects had no history of significant medical illness or major head trauma. All subjects had no use of any psychotropic medications or herbal products during the last 6 months before their participation. All women of childbearing age were required to have a negative pregnancy test during the screening process and before radiotracer injection on each study day. All healthy women were included; we did not exclude subjects for menstrual cycle irregularities or hormonal birth control. Menstrual cycle phase data were not collected. After complete description of the study to the subjects, written informed consent was obtained.

Alcohol drinkers were given a variety of assessments to determine demographic and other behavioral information. Assessments of alcohol drinking behavior included the Timeline FollowBack (Sobell and Sobell, 1993), Clinical Institute Withdrawal Assessment of Alcohol Scale, Revised (CIWA-Ar) (Sullivan et al, 1989), Alcohol Dependence Scale (ADS) (Skinner and Hom, 1984), and assessments of mood included the Beck Depression Inventory (BDI) (Beck et al, 1961) and the Center for Epidemiologic Studies Depression Scale (CES-D) (Radloff 1977).

\section{$\left[{ }^{123}\right] \beta$-CIT SPECT and Magnetic Resonance Imaging Scans}

The radiotracer $\left[{ }^{123}\right] \beta$-CIT was synthesized from the tributylstannyl precursor, with a radiochemical purity $>97 \%$, as previously described (Baldwin et al, 1993). On day 1 of the study, subjects were pretreated with stable iodine approximately $30 \mathrm{~min}$ before radiotracer injection to limit thyroid uptake of ${ }^{123} \mathrm{I}$. $\left[{ }^{123}\right] \beta$-CIT was administered by bolus intravenous injection to alcohol drinkers $220.5 \pm 23.3 \mathrm{MBq}$ and control subjects $223.3 \pm 8.7 \mathrm{MBq}$. Subjects returned the next day and were scanned 21-24 $\mathrm{h}$ after radiotracer injection. Before imaging, five external fiducial markers of ${ }^{123}$ I were placed on the subject's head. One 24-min emission scan and one 15-min simultaneous transmission and emission scan were obtained on a Picker Prism 3000 three-headed camera (Phillips, Cleveland, OH) equipped with a low-energy, ultra-high resolution fan-beam collimator (photopeak window $159 \mathrm{keV} \pm 10 \%$, matrix $128 \times 128$ ) with a uniform sensitivity across the field of view. A ${ }^{57} \mathrm{Co}$-distributed source was measured with each experiment to control for daily variation in camera sensitivity. The axial resolution (full width at half maximum) of the camera was $12.2 \mathrm{~mm}$, measured with a ${ }^{123} \mathrm{I}$ line source in water in a cylindrical phantom. Blood was drawn on day 1 before radiotracer injection and approximately $21 \mathrm{~h}$ after injection to determine radiotracer metabolism and protein binding, or $\mathrm{f}_{\mathrm{P}}$.

Magnetic resonance imaging (MRI) was performed on a 1.5 Tesla GE Signa device $(\mathrm{TR}=25 \mathrm{~ms}, \mathrm{TE}=5 \mathrm{~ms}$, number of excitations $=2$, matrix $=256 \times 256$ pixels, and field of view $=24 \mathrm{~cm}$ ).

\section{Image Analysis and Outcome Measure}

$\left[{ }^{123}\right] \beta$-CIT labels DA and 5-HT transporters in a regionspecific manner. Specifically, $\left[{ }^{123}\right] \beta$-CIT labels DA transporters in the striatum and 5-HT transporters in the diencephalon and brainstem (Laruelle et al, 1993). SPECT images were analyzed with an MRI-based region-of-interest (ROI) approach as previously described (Staley et al, 2001, 2006). Briefly, emission data were reconstructed and a nonuniform attenuation correction was applied. Then, the MRI was co-registered to the emission scan to provide an anatomical guide for the placement of two-dimensional ROIs using MEDx software (Medical Numerics Inc.). The chosen ROIs are those known to contain DA transporters, eg caudate and putamen, which are averaged into one striatal region; 5HT transporters, eg diencephalon and brainstem; and the cerebellum, which is used a background region. Two raters conducted the analysis. Variability between the raters was less than $12 \%$ across ROIs. The mean of the two raters is reported.

The primary outcome measure used was $\mathrm{BP}_{\mathrm{P}}$, which is proportional to the binding potential (binding potential, in $\mathrm{ml} / \mathrm{g}$, equal to receptor number divided by receptor affinity) defined as follows: (specific-nondisplaceable uptake)/total parent in plasma. It is computed as (ROI activitycerebellum)/total parent in plasma. The cerebellum, which has no detectable levels of DA transporters and minimal levels of 5-HT transporters, is used as the background region. To control for differences in radiotracer metabolism and protein binding, we compared the measures of total plasma parent concentration, $\mathrm{f}_{\mathrm{P}}$ (protein binding), and free plasma parent concentration, defined as total parent concentration $\times f_{P}$, between groups.

\section{Statistical Analysis}

All outcomes were tested for normality using KolmogorovSmirnov test statistics and normal probability plots. DA and 5-HT transporter availability and $V_{2}$ values (cerebellum uptake/total parent) were approximately normal. Radiotracer metabolism and protein binding values, eg $f_{P}$, free parent, and total parent, were approximately normal after log transformation and thus, the log-transformed values were used for analysis. Each outcome was evaluated using two-way ANOVA models where group (alcohol drinkers $v s$ controls) and smoking status (smokers vs nonsmokers) were included as between-subject explanatory factors. Group comparisons within each level of smoking status were made to interpret significant interactions. These latter two comparisons were adjusted for type I error using the Bonferroni correction. In the above models, age and gender were considered as potential covariates but were dropped for parsimony as neither of these variables was significant. Potential associations between brain and alcohol measures were assessed using correlation analysis. Analyses were performed using SAS, version 9.1 (SAS Inc., Cary, NC) and all tests were considered statistically significant at $P \leqslant 0.05$.

\section{RESULTS}

\section{Group Characteristics}

A total of 28 subjects composed of 14 controls and 14 alcohol drinkers with 8 nonsmokers and 6 smokers per 
group participated in the study (Table 1). Alcohol drinkers were imaged between 1 and 5 days after their last drink. Alcohol smokers and nonsmokers did not differ significantly in average number of drinks per month, years drinking, or the ADS. Alcohol smokers and control smokers did not differ significantly in numbers of cigarettes smoked per day, years smoked, or FTND. Control subjects denied drinking alcohol within the month before the scan, no control subject reported drinking more than eight drinks in a 1-year period, and control subjects denied use of other illicit or psychotropic drugs.

\section{DA Transporter Availability}

Overall striatal DA transporter levels were significantly higher in alcohol drinkers vs controls $(\mathrm{F}(1,24)=4.9$, $P=0.04)$. In addition, the group $\times$ smoking interaction was significant $(\mathrm{F}(1,24)=4.4, P=0.05)$ which was driven by greater DA transporter availability among alcohol nonsmokers $v s$ control nonsmokers $(\mathrm{F}(1,24)=10.9$, adjusted $P=0.006)$, with no difference between alcohol smokers and control smokers $(\mathrm{F}(1,24)=0.01$, adjusted $P=1.0)$ (see Figure 1 and Table 2).

\section{5-HT Transporter Availability}

A significant group $\times$ smoking status interaction was observed when assessing 5-HT transporter availability in both the diencephalon $(\mathrm{F}(1,24)=7.7, P=0.01)$ and brainstem $\quad(\mathrm{F}(1,24)=14.1, \quad P=0.001) . \quad$ Specifically, alcohol nonsmokers had significantly greater diencephalon $(\mathrm{F}(1,24)=6.2, \quad$ adjusted $P=0.04) \quad$ and brainstem $(\mathrm{F}(1,24)=23.5$, adjusted $P<0.0002) \quad 5$-HT transporter availability compared to control nonsmokers, whereas diencephalon $(\mathrm{F}(1,24)=2.3$, adjusted $P=0.30)$ and brainstem $(\mathrm{F}(1,24)=0.58$, adjusted $P=0.90) 5$-HT transporter availability did not differ significantly between alcohol smokers and control smokers (see Figure 2 and Table 2).

$V_{2}$ values (cerebellum uptake/total parent) were compared between groups to ensure that group differences were not due to differences in nondisplaceable uptake. Again, a significant interaction was observed between group and smoking status $(\mathrm{F}(1,24)=11.3, P=0.003)$, which was driven by significantly higher $V_{2}$ levels among alcohol nonsmokers compared to control nonsmokers $(\mathrm{F}(1,24)=22.8$, adjusted $P<0.0002)$, with no group differences observed among smokers $(\mathrm{F}(1,24)=0.1$, adjusted $P=1.0)$. Higher $V_{2}$ levels could be attributed to the small but detectable number of 5-HT transporters in the vermis of the cerebellum (Backstrom et al, 1989; Laruelle et al, 1988). Importantly, cerebellar $V_{2}$ levels were not lower in the alcohol nonsmokers as would be expected if there was significant atrophy of the cerebellum, indicating that the higher numbers of DA and 5-HT transporters in other brain areas are not due to group differences in nondisplaceable uptake.

Table 2 DA and 5-HT Transporter Availability by Alcohol Drinking and Smoking Status: BP Mean (SD)

\begin{tabular}{|c|c|c|c|c|c|c|c|c|}
\hline & \multicolumn{2}{|c|}{ Nonsmokers } & \multirow[t]{2}{*}{ Difference (\%) } & \multirow[t]{2}{*}{$P$-value } & \multicolumn{2}{|c|}{ Smokers } & \multirow[t]{2}{*}{ Difference (\%) } & \multirow[t]{2}{*}{$P$-value } \\
\hline & Controls $(n=8)$ & Drinkers $(n=8)$ & & & Controls $(n=6)$ & Drinkers $(n=6)$ & & \\
\hline Striatum & $306(47)$ & $4 \mid I(43)$ & 26 & 0.006 & $311(87)$ & $313(80)$ & I & 1.0 \\
\hline \multicolumn{9}{|l|}{ 5-HT transporter } \\
\hline
\end{tabular}

Striatal Dopamine Transporters
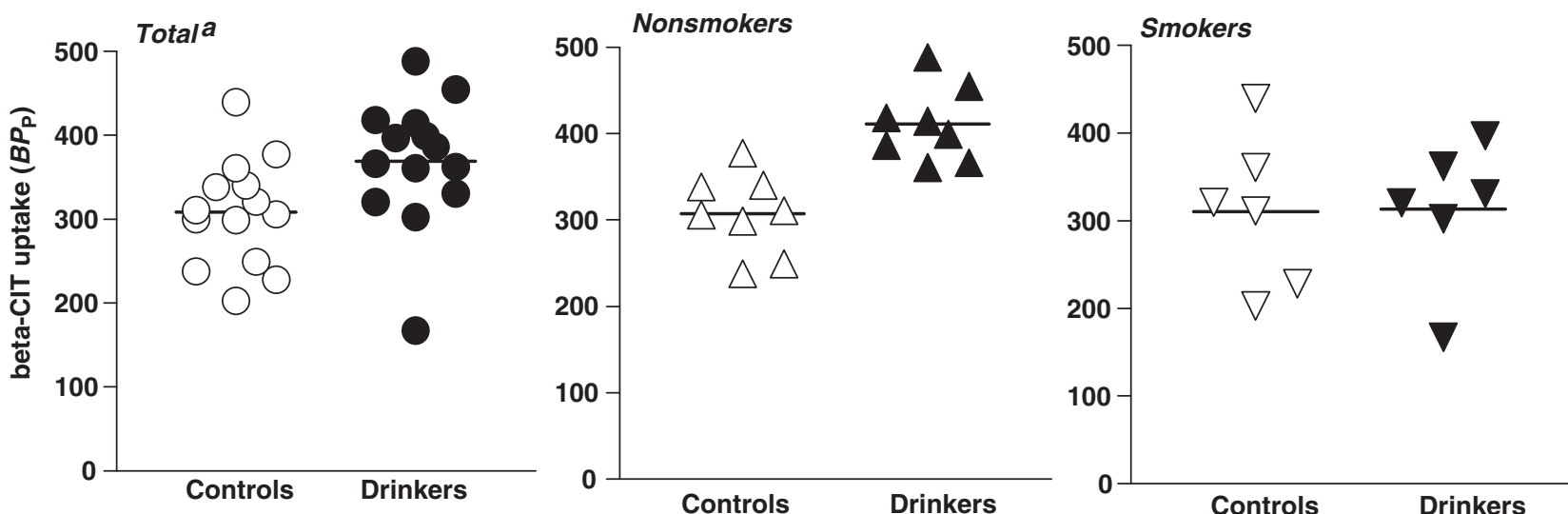

Figure I Striatal $\left[{ }^{123} \mid\right] \beta$-CIT binding in controls and alcohol drinkers in the total group and by smoking status. ${ }^{2}$ The bar represents the mean in each group. Percent difference was calculated as ((alcohol drinker-control)/alcohol drinker $\times 100)$. In the total group, there was a $16 \%$ difference $(P=0.04)$, in the nonsmokers a $26 \%$ difference $(P=0.006)$, and in the smokers a $1 \%$ difference $(P=1.0)$. 
Diencephalon 5-HT Transporters
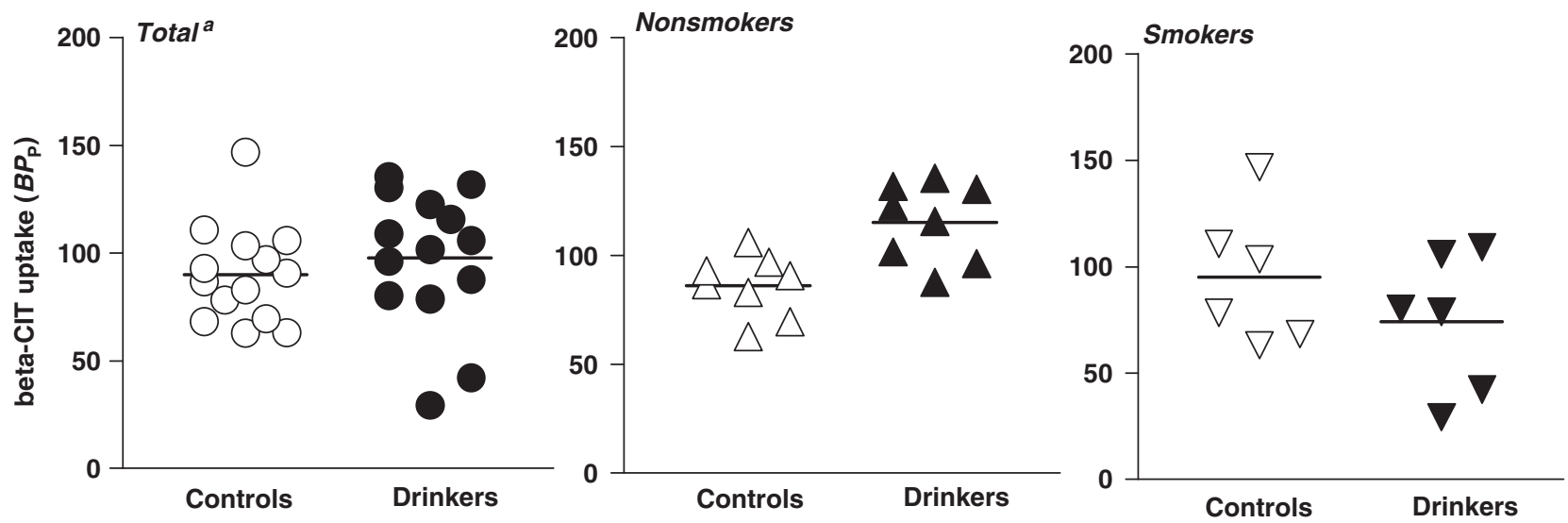

Brainstem 5-HT Transporters
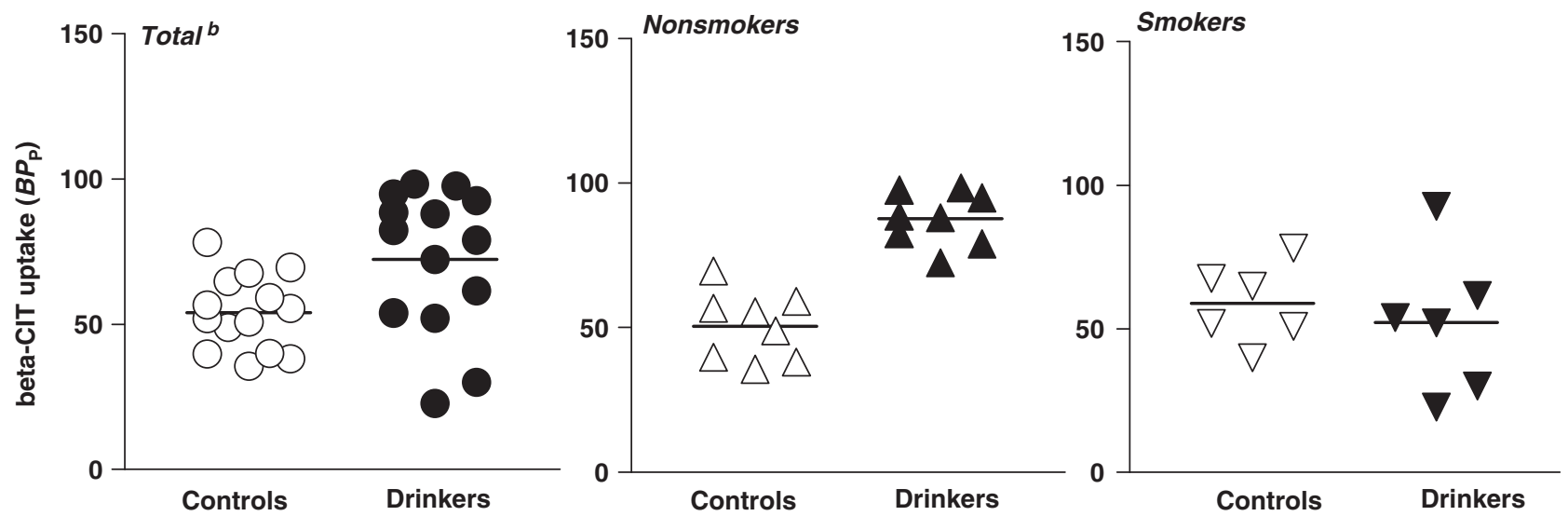

Figure 2 Diencephalon and brainstem $\left[{ }^{123} \mid\right] \beta$-CIT binding in controls and alcohol drinkers in the total group and by smoking status. ${ }^{a} \mid n$ the total group,

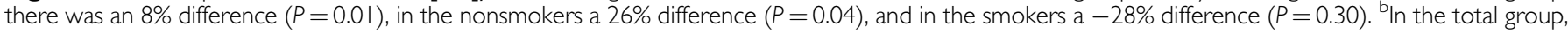
there was a $25 \%$ difference $(P=0.00 \mathrm{I})$, in the nonsmokers a $42 \%$ difference $(P<0.0002)$, and in the smokers a $-13 \%$ difference $(P=0.90)$.

\section{Radiotracer Metabolism and Protein Binding}

Radiotracer metabolism and protein binding values were also examined between groups. Significantly lower levels of both total parent $(\mathrm{F}(1,24)=8.5, P=0.008)$ and free parent, defined as $\mathrm{f}_{\mathrm{P}} \times$ total parent $(\mathrm{F}(1,24)=6.3, P=0.02)$, were observed in alcohol drinkers compared to controls. Although there were no significant main or interactive effects of smoking on each of these variables (all $P$ 's $>0.28$ ), the observed group differences were primarily driven by significantly lower total $(\mathrm{F}(1,24)=9.3$, adjusted $P=0.012)$ and free $(\mathrm{F}(1,24)=7.4$, adjusted $P=0.02)$ parent levels among alcohol nonsmokers vs control nonsmokers. This finding suggests that alcohol nonsmokers had faster metabolism of $\left[{ }^{123} \mathrm{I}\right] \beta$-CIT. By using the outcome measure $\mathrm{BP}_{\mathrm{P}}$, we correct for group differences in radiotracer metabolism.

\section{Correlations Between DA and 5-HT Transporters and Alcohol Use History}

Pearson's correlations were performed between striatal DA and brainstem and diencephalon 5-HT transporter availability and alcohol measures including days since last drink, average drinks per month, years of drinking, and scores on the ADS, BDI, and CES-D. There was a significant positive correlation between days since last drink and diencephalon $(r=0.60, P=0.02)$ and brainstem $(r=0.54, P=0.05) 5-\mathrm{HT}$ availability (see Figure 3 ). However, stratified analysis revealed these associations present in nonsmokers ( $r=0.79, P=0.02$ and $r=0.79, P=0.02$ for diencephalon and brainstem, respectively) but not smokers $(r=0.07$, $P=0.90$ and $r=0.03, P=0.95$, respectively). There were no significant correlations between striatal DA and brainstem and diencephalon 5-HT transporter availability and other alcohol or depression measures.

\section{DISCUSSION}

In the present study, we report significantly higher striatal DA transporters in alcoholic nonsmokers but not alcoholic smokers during acute withdrawal. A similar pattern was noted also for 5-HT transporters with higher diencephalon and brainstem availability in the alcoholic nonsmokers but not alcoholic smokers. The significant positive correlation between diencephalon and brainstem 5-HT transporter availability and days since last drink in the alcoholic nonsmokers suggests that the higher availability was due to 

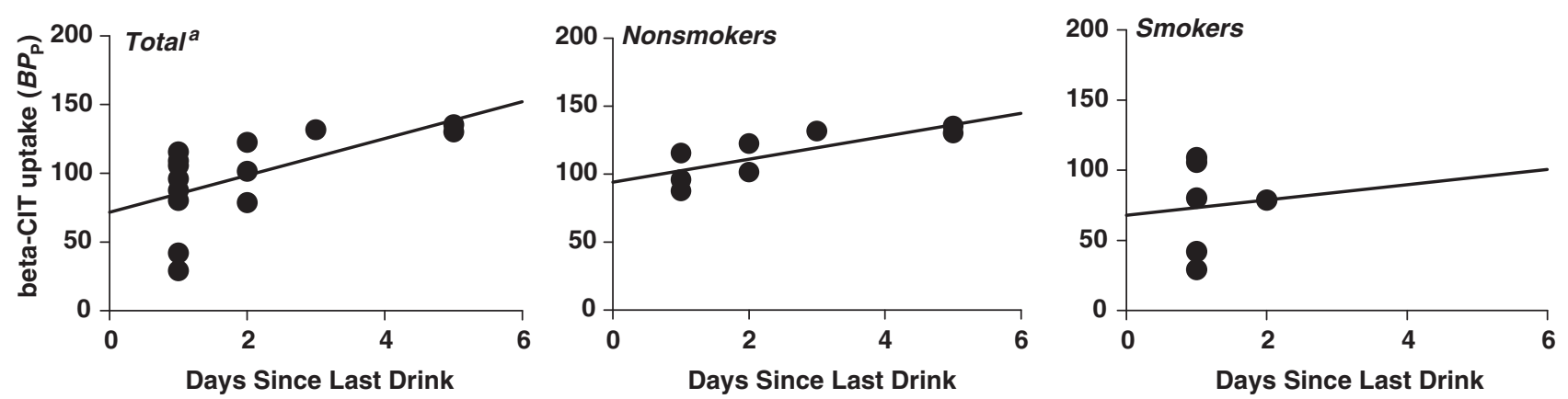

Brainstem 5-HT Transporters
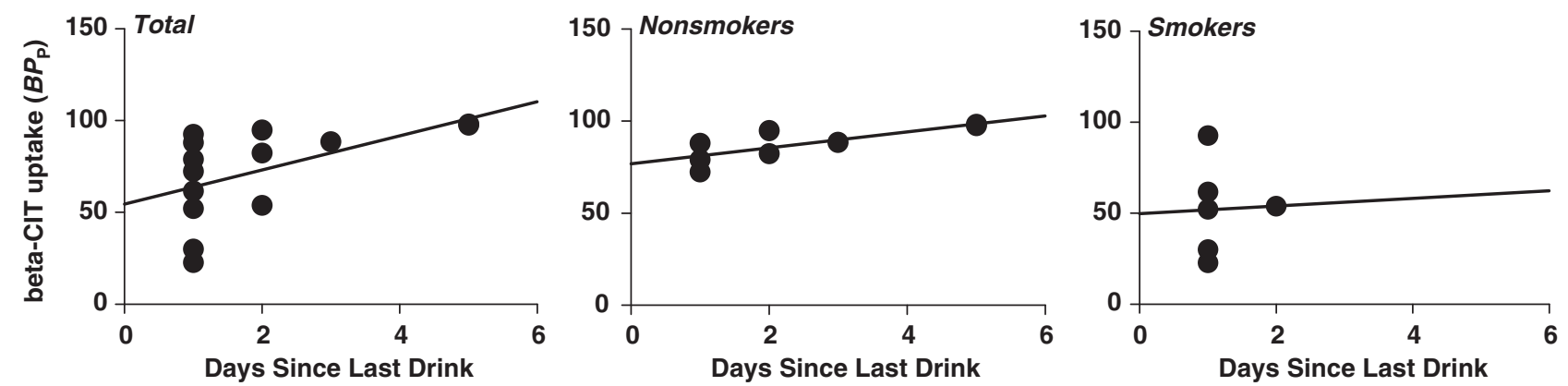

Figure 3 Diencephalon and brainstem [ $\left.{ }^{123} \mathrm{l}\right] \beta$-CIT binding in alcohol drinkers in the total group and by smoking status as a function of days since last drink. ${ }^{a}$ Significant linear regression coefficients were found in the total group and in the nonsmokers, but not the smokers for both brain regions.

a compensatory increase in response to acute withdrawal from alcohol.

Given that $V_{2}$ is an indirect measure of cerebellar atrophy and is significantly higher in alcohol nonsmokers compared to controls, it is unlikely that the higher DA and 5-HT transporter availability is due to atrophy of the reference region, eg the cerebellum. Although it is unexpected to have higher numbers of $V_{2}$ in the reference region, this is not surprising given that low, but detectable levels of 5-HT transporters have been measured in the vermis of the cerebellum (Backstrom et al, 1989; Laruelle et al, 1988). Although studies in control subjects demonstrate no significant measurable levels of 5-HT transporters in the cerebellum (Staley et al, 2001), after alcohol exposure and withdrawal the measurable numbers may become more significant. This theory needs to be validated in a future study with a more selective paradigm.

This study differs from studies showing a decrease in DA transporter availability in recently abstinent alcoholics in vivo up to 4 weeks of abstinence (Laine et al, 1999), post mortem, up to $10 \mathrm{~h}$ after the last drink (Tupala et al, 2001), and after chronic alcohol and 1 day of withdrawal in vervet monkeys (Mash et al, 1996), but is consistent with results indicating increased DA transporter availability in alcoholpreferring vs nonpreferring monkeys (Mash et al, 1996). Notably, there was a decrease in DA transporter availability after chronic alcohol compared to controls, which then increased during acute withdrawal (Laine et al, 1999; Mash et al, 1996) and in some subjects approached or surpassed the level of DA transporter availability in control subjects (Laine et al, 1999).

The main differences between previous studies examining DA transporter availability in alcoholics and controls and the current study are (1) the systematic examination of tobacco smoking in the current study and (2) the severity of alcohol dependence. First, higher availability of DA transporters in alcohol nonsmokers but not smokers compared to controls suggests that smoking suppresses the alcohol-induced increase in DA transporter availability. The previous in vivo study (Laine et al, 1999) did not control for smoking, thus it is not clear whether there is a similar effect of comorbid tobacco smoking in chronic severe alcohol dependence. Second, subjects in the current study exhibit a range of alcohol consumption, from heavy drinkers to subjects that meet dependence (eg a range of 25-428 drinks per month), and did not require detoxification or inpatient hospitalization before withdrawal. Thus, this study may highlight a difference in DA transporter availability between alcoholics and heavy drinkers. It is possible that alcoholics have an altered 'set point' in DA transporter availability compared to both healthy controls and to heavy alcohol drinkers (Koob, 2003). Lower DA transporters in alcohol drinkers have been hypothesized to be due to a downregulation of DA transporters in response to chronic alcohol consumption. In this study the subjects had been drinking for an average of 19 years (range 6-40 years) suggesting that the chronicity of drinking alone does not lead to lower DA transporters, but the amount of alcohol consumed is also a key part. It is possible that a subsyndromal level of alcohol drinking leads to a compensatory increase in DA transporter availability, measured during acute withdrawal. Indeed, it is interesting that Mash et al, 1996 similarly found increased DA transporters in alcohol-preferring monkeys that had not chronically consumed large quantities of alcohol, and notably were nicotine naive. Thus, a higher DA transporter availability is likely 
linked to lower DA tone, and may indicate a vulnerability to alcohol dependence. Taken together, these studies suggest that moderate to heavy drinking leads to higher DA transporter availability that is suppressed by tobacco smoking. More severe alcohol dependence may be associated with lower DA transporters and may also be modulated by tobacco smoking. Studies designed to address this question in more severe alcoholic populations need to be carried out within the first week of alcohol withdrawal.

These results extend the findings from previous studies that demonstrated lower 5-HT transporter availability in alcoholics abstinent for $>3$ weeks (Heinz et al, 1998b; Szabo et al, 2004). Specifically, lower midbrain and brainstem 5-HT transporter availability was found in alcohol-dependent men after 3-5 weeks (Heinz et al, 1998b) and at least 2 years (Szabo et al, 2004) of abstinence compared to healthy controls, which was correlated with depression and anxiety during withdrawal (Heinz et al, 1998b). A more recent study using $\left[{ }^{11} \mathrm{C}\right] \mathrm{DASB}$ reported no difference in 5-HT transporter availability between alcoholics (smokers and nonsmokers), who were abstinent an average of 14 days, and control nonsmokers (Brown et al, 2007), which is a more selective ligand for 5-HT transporters than $\left[{ }^{123} \mathrm{I}\right] \beta$-CIT. In the present study we observed higher 5-HT transporter availability in both the diencephalons and brainstem of alcoholic nonsmokers vs control nonsmokers that was not evident in the smokers. The significant positive correlation between diencephalon and brainstem 5-HT transporter availability and days since last drink suggests that during acute withdrawal, there is a compensatory increase in 5-HT transporters in nonsmokers but not smokers, suggesting that smoking suppresses the alcohol-induced increase in 5-HT transporter availability over the first week of abstinence. Of note, there are limitations to $\left[{ }^{123}\right] \beta$-CIT SPECT measurement of 5 -HT transporter availability, eg the radiotracer may be influenced by endogenous 5-HT (Heinz et al, 2004) and there are difficulties in quantification due to the low signal in the neocortex (Kuikka et al, 1995; vanDyck et al, 2000). However, the main finding of the current study lies in the modulation of 5-HT transporter availability by comorbid tobacco smoking and heavy drinking. Previous in vivo 5-HT transporter studies attempted to control for smoking in the alcoholic samples; however the studies did not include sufficient control smokers to assess systematically the effects of smoking between all groups. Specifically, the studies included either no control smokers (Brown et al, 2007) or two control smokers (Heinz et al, 1998b; Szabo et al, 2004).

There are several reasons that DA and 5-HT transporter availability may differ between alcoholic smokers and nonsmokers. First, genetic differences may have a role such that alcoholics who smoke may be genetically distinct from alcoholics who do not smoke, and there is evidence to suggest that there is a common genetic component that contributes to alcohol and nicotine dependence (True et al, 1999). There may be a unique genetic contribution of the DA transporter gene to striatal DA transporter availability in alcoholics that is also correlated with alcohol withdrawal severity (Heinz et al, 2000a), and a possible link exists between reduced 5-HT transporter availability with the 5 -HT genotype in alcoholics (Heinz et al, 2000b). Second, there may be neurochemical differences between alcohol drinkers who smoke and those who do not smoke. Tobacco smoke contains up to 4000 chemicals including nicotine, and monoamine oxidase inhibitors (MAOIs) that alter the activity of DA and 5-HT. Specifically, chronic MAO inhibition increases extracellular (Lamensdorf et al, 1996) and tissue (Ilani et al, 2000) DA levels. Consistently, low platelet MAO activity has been reported in both alcoholics (Hallman et al, 1991; von Knorring et al, 1985; von Knorring et al, 1987) and tobacco smokers (Von Knorring and Oreland, 1985). We propose that chronic MAO inhibition from tobacco smoking increases DA release, and together with the increased DA release from heavy alcohol drinking leads to a downregulation of the DA transporter in alcoholic smokers compared to the alcoholic nonsmokers. Notably, a previous study found no direct effect of tobacco smoking on the DA transporter (Staley et al, 2001), which implies there is an interaction of tobacco smoking and alcohol drinking at the DA transporter.

There are several limitations to the study. First, due to the small sample size, the results should be interpreted with caution and they require replication. Specifically, there is some between-subject variability in the tobacco smoker groups, most notably in DA transporter availability. However, the data were analyzed in the presence and absence of the subjects with the lowest DA and 5-HT transporter availability and significance of the results was maintained. Second, although it is known that there are sex differences in the availability of both 5-HT (Staley et al, 2001) and DA (Lavalaye et al, 2000; Mozley et al, 2001; Staley et al, 2001) transporter availability, there was no effect of sex in the current study. These previous studies were conducted in healthy subjects. One issue with controlling for menstrual cycle phase or hormone fluctuations in studies with problem drinkers and smokers is that alcohol (Emanuele et al, 2002) and tobacco smoking (Brown et al, 1988; Windham et al, 1999) can disrupt the menstrual cycle making it difficult to control for the menstrual cycle in this population. We did not control for hormonal fluctuations or menstrual cycle phase in the current study and this will have to be evaluated in a future study. Third, there are limitations to $\left[{ }^{123} \mathrm{I}\right] \beta$-CIT SPECT. Specifically, the radiotracer is not selective, but measures both striatal DA and brainstem and diencephalon 5-HT transporters. In addition, $\left[{ }^{123} \mathrm{I}\right] \beta$-CIT is not sensitive to the measurement of DA transporters in the cortex, which were recently found to be higher in post-mortem brain of alcohol-dependent individuals vs controls (Tupala et al, 2006).

In summary, high striatal DA and diencephalon and brainstem 5-HT transporter availability in alcohol nonsmokers during acute abstinence may reflect a neuroadaptive response to acute alcohol withdrawal, and/or a vulnerability or transition to more severe alcohol dependence. This effect is suppressed by tobacco smoking and may have implications for the design of treatment plans for alcohol drinkers who also smoke. Although additional studies are needed, it may be speculated that by suppressing the neuroadaptive change in DA and 5-HT transporters during acute abstinence, tobacco smoking may alleviate some of the withdrawal symptoms from alcohol. This suggests that alcoholic smokers desiring to quit drinking and smoking simultaneously should be encouraged to use 
nicotine replacement strategies or nicotinic agonist medication to help manage alcohol withdrawal symptoms.

\section{ACKNOWLEDGEMENTS}

This work was supported by the Department of Veterans Affairs (via support for the Alcohol Research Center), US Veterans Affairs VISN 1 Mental Illness Research Education and Clinical Center (MIRECC), National Institute of Alcohol and Alcoholism (KO1AA00288; RO1 AA-11321; K05 AA-14906-01; I-P50 AA-12870-03), and National Institute of Drug Abuse (KO1DA02065; KO2DA21863).

\section{DISCLOSURES/CONFLICT OF INTEREST}

Dr Krystal serves as a consultant to AstraZeneca, BristolMyers Squibb, Cypress Bioscience Inc., Eli Lilly and Co., Forest Laboratories, GlaxoSmithKline, Houston Pharma, Janssen Research Foundation, Lohocla Research Corporation, Merz Pharmaceuticals, Organon Pharmaceuticals/ Division of Schering-Plough Research Institute, Pfizer Pharmaceuticals, Schering Corporation acting through Schering-Plough Research Institute Division, Shire Pharmaceuticals, Takeda Industries, Tetragenex Pharmaceuticals, Transcept Pharmaceuticals, UCB Pharma, and US Micron. Dr Krystal has patents pending for glutamatergic agents for psychiatric disorders and oral ketamine for depression. No other authors report any conflicts of interest.

\section{REFERENCES}

Backstrom I, Bergstrom M, Marcusson J (1989). High affinity $\left[{ }^{3} \mathrm{H}\right]$ paroxetine binding to serotonin uptake sites in human brain tissue. Brain Res 486: 261-268.

Baldwin R, Zea-Ponce Y, Zoghbi S, Laurelle M, Al-Tikriti M, Sybirska E et al. (1993). Evaluation of the monoamine uptake site ligand $\left[{ }^{123} \mathrm{I}\right]$ methyl $3 \beta$-(4-iodophenyl)-tropane- $2 \beta$-carboxylate $\left(\left[{ }^{123} \mathrm{I}\right] \beta\right.$-CIT) in non-human primates: pharmacokinetics, biodistribution and SPECT brain imaging coregistered with MRI. Nucl Med Biol 20: 597-606.

Beck S, Ward C, Mendelsohn M, Erbaugh J (1961). An inventory for measuring depression. Arch Gen Psychiatry 4: 561-571.

Brown AK, George DT, Fujita M, Liow JS, Ichise M, Hibbeln J et al. (2007). PET $\left[{ }^{11} \mathrm{C}\right] \mathrm{DASB}$ imaging of serotonin transporters in patients with alcoholism. Alcohol Clin Exp Res 31: 28-32.

Brown S, Vessey M, Stratton I (1988). The influence of method of contraception and cigarette smoking on menstrual patterns. $\mathrm{Br} \mathrm{J}$ Obstet Gynecol 95: 905-910.

Carmody T, Brischetto C, Matarazzo J, O'Donnell R, Connor W (1985). Co-occurrent use of cigarettes, alcohol, and coffee in healthy, community-living men and women. Health Psychol 4: 323-335.

Chastain G (2006). Alcohol, neurotransmitter systems, and behavior. J Gen Psychol 133: 329-335.

Dawson D (2000). Drinking as a risk factor for sustained smoking. Drug Alcohol Depen 59: 235-249.

Di Chiara G, Imperato A (1988). Drugs abused by humans preferentially increase synaptic dopamine concentrations in the mesolimbic system of freely moving rats. Proc Natl Acad Sci USA 85: 5274-5278.

Emanuele MA, Wezeman F, Emanuele NV (2002). Alcohol's effects on female reproductive function. Alcohol Res Health 26: 274-281.
Funk D, Marinelli PW, Le AD (2006). Biological processes underlying co-use of alcohol and nicotine: neuronal mechanisms, cross-tolerance, and genetic factors. Alcohol Res Health 29: 186-192.

Grant BF, Hasin DS, Chou SP, Stinson FS, Dawson DA (2004). Nicotine dependence and psychiatric disorders in the United States: results from the national epidemiologic survey on alcohol and related conditions. Arch Gen Psychiatry 61: 1107-1115.

Hallman J, von Knorring L, Edman G, Oreland L (1991). Personality traits and platelet monoamine oxidase activity in alcoholic women. Addict Behav 16: 533-541.

Heinz A, Goldman D, Jones DW, Palmour R, Hommer D, Gorey JG et al. (2000a). Genotype influences in vivo dopamine transporter availability in human striatum. Neuropsychopharmacology 22: 133-139.

Heinz A, Higley JD, Gorey JG, Saunders RC, Jones DW, Hommer D et al. (1998a). In vivo association between alcohol intoxication, aggression, and serotonin transporter availability in nonhuman primates. Am J Psychiatry 155: 1023-1028.

Heinz A, Jones DW, Gorey JG, Bennet A, Suomi SJ, Weinberger DR et al. (2003). Serotonin transporter availability correlates with alcohol intake in non-human primates. Mol Psychiatry 8: 231-234.

Heinz A, Jones DW, Mazzanti C, Goldman D, Ragan P, Hommer D et al. (2000b). A relationship between serotonin transporter genotype and in vivo protein expression and alcohol neurotoxicity. Biol Psychiatry 47: 643-649.

Heinz A, Jones DW, Zajicek K, Gorey JG, Juckel G, Higley JD et al. (2004). Depletion and restoration of endogenous monoamines affects beta-CIT binding to serotonin but not dopamine transporters in non-human primates. J Neural Transm Suppl 68: $29-38$.

Heinz A, Mann K, Weinberger DR, Goldman D (2001). Serotonergic dysfunction, negative mood states, and response to alcohol. Alcohol Clin Exp Res 25: 487-495.

Heinz A, Ragan P, Jones DW, Hommer D, Williams W, Knable MB et al. (1998b). Reduced central serotonin transporters in alcoholism. Am J Psychiatry 155: 1544-1549.

Ilani T, Lamensdorf I, Finberg JP (2000). Selective monoamine oxidase subtype inhibition and striatal extracellular dopamine in the guinea-pig. Br J Pharmacol 130: 1992-1998.

Janhunen S, Ahtee L (2007). Differential nicotinic regulation of the nigrostriatal and mesolimbic dopaminergic pathways: implications for drug development. Neurosci Biobehav Rev 31: 287-314.

Koob GF (2003). Alcoholism: allostasis and beyond. Alcohol Clin Exp Res 27: 232-243.

Kuikka J, Tihonen J, Bergstrom K, Karhu J, Hartikainen P, Viinamaki $\mathrm{H}$ et al. (1995). Imaging of serotonin and dopamine transporters in the living human brain. Eur J Nucl Med 22: 346-350.

Laine TP, Ahonen A, Torniainen P, Heikkila J, Pyhtinen J, Rasanen $P$ et al. (1999). Dopamine transporters increase in human brain after alcohol withdrawal. Mol Psychiatry 4: 189-191, 104-5.

Lamensdorf I, Youdim MB, Finberg JP (1996). Effect of long-term treatment with selective monoamine oxidase A and B inhibitors on dopamine release from rat striatum in vivo. J Neurochem 67: 1532-1539.

Laruelle M, Baldwin R, Malison R, Zea-Ponce Y, Zoghbi S, AlTikriti M et al. (1993). SPECT imaging of dopamine and serotonin transporters with $\left[{ }^{123} \mathrm{I}\right] \beta-\mathrm{CIT}$ : pharmacological characterization of brain uptake in nonhuman primates. Synapse 13: 295-309.

Laruelle M, Vanisberg M, Maloteaux J (1988). Regional and subcellular localization in human brain of $\left[{ }^{3} \mathrm{H}\right]$ paroxetine binding, a marker of serotonin uptake sites. Biol Psychiatry 24: 299-309.

Lavalaye J, Booij J, Reneman L, Habraken J, Royen Ev (2000). Effect of age and gender on dopamine transporter imaging with 
$\left[{ }^{123}\right.$ I]FP-CIT SPET in healthy volunteers. Eur J Nucl Med 27: 867-869.

Mash DC, Staley JK, Doepel FM, Young SN, Ervin FR, Palmour RM (1996). Altered dopamine transporter densities in alcoholpreferring vervet monkeys. Neuroreport 7: 457-462.

McKee SA, Falba T, O'Malley SS, Sindelar J, O’Connor PG (2007). Smoking status as a clinical indicator for alcohol misuse in US adults. Arch Intern Med 167: 716-721.

Meyerhoff DJ, Tizabi Y, Staley JK, Durazzo TC, Glass JM, Nixon SJ (2006). Smoking comorbidity in alcoholism: neurobiological and neurocognitive consequences. Alcohol Clin Exp Res 30: 253-264.

Miller N, Gold M (1998). Comorbid cigarette and alcohol addiction: epidemiology and treatment. J Addict Dis 17: 55-66.

Mozley LH, Gur RC, Mozley PD, Gur RE (2001). Striatal dopamine transporters and cognitive functioning in healthy men and women. Am J Psychiatry 158: 1492-1499.

Radloff L (1977). The CES-D scale: a self-report depression scale for research in the general population. Applied Psychol Meas 1: 385-401.

Repo E, Kuikka JT, Bergstrom KA, Karhu J, Hiltunen J, Tiihonen J (1999). Dopamine transporter and D2-receptor density in lateonset alcoholism. Psychopharmacology (Berl) 147: 314-318.

Seibyl JP, Laruelle M, van Dyck CH, Wallace E, Baldwin RM, Zoghbi S et al. (1996). Reproducibility of iodine-123-beta-CIT SPECT brain measurement of dopamine transporters. J Nucl Med 37: 222-228.

Seibyl JP, Marek K, Sheff K, Baldwin RM, Zoghbi S, Zea-Ponce Y et al. (1997). Test/retest reproducibility of iodine-123-betaCIT SPECT brain measurement of dopamine transporters in Parkinson's patients. J Nucl Med 38: 1453-1459.

Seth P, Cheeta S, Tucci S, File SE (2002). Nicotinic-serotonergic interactions in brain and behaviour. Pharmacol Biochem Behav 71: 795-805.

Skinner H, Hom J (1984). Alcohol Dependence Scale (ADS) User's Guide. Addiction Research Foundation: Toronto.

Sobell L, Sobell M (1993). Timeline Followback: a technique for assessing self-reported ethanol consumption. In: Allen J, Litten R (eds) Techniques to Assess Alcohol Consumption. Humana Press: New Jersey.

Staley J, Krishnan-Sarin S, Zoghbi S, Tamagnan G, Fujita M, Seibyl J et al. (2001). Sex differences in [123I]beta-CIT SPECT measures of dopamine and serotonin transporter availability in healthy smokers and nonsmokers. Synapse 41: 275-284.

Staley JK, Gottschalk C, Petrakis IL, Gueorguieva R, O'Malley S, Baldwin $\mathrm{R}$ et al. (2005). Cortical gamma-aminobutyric acid type A-benzodiazepine receptors in recovery from alcohol dependence: relationship to features of alcohol dependence and cigarette smoking. Arch Gen Psychiatry 62: 877-888.

Staley JK, Sanacora G, Tamagnan G, Maciejewski PK, Malison RT, Berman RM et al. (2006). Sex differences in diencephalon serotonin transporter availability in major depression. Biol Psychiatry 59: 40-47.

Sullivan J, Sykora K, Schneiderman J, Naranjo C, Sellers E (1989). Assessment of alcohol withdrawal: the revised Clinical Institute Withdrawal Assessment for Alcohol Scale (CIWA-Ar). $\mathrm{Br} \mathrm{J}$ Addiction 84: 1353-1357.

Szabo Z, Owonikoko T, Peyrot M, Varga J, Mathews WB, Ravert HT et al. (2004). Positron emission tomography imaging of the serotonin transporter in subjects with a history of alcoholism. Biol Psychiatry 55: 766-771.

Tiihonen J, Kuikka J, Bergstrom K, Hakola P, Karhu J, Ryynanen OP et al. (1995). Altered striatal dopamine re-uptake site densities in habitually violent and non-violent alcoholics. Nat Med 1: 654-657.

True WR, Xian H, Scherrer JF, Madden PA, Bucholz KK, Heath AC et al. (1999). Common genetic vulnerability for nicotine and alcohol dependence in men. Arch Gen Psychiatry 56: 655-661.

Tupala E, Halonen P, Tiihonen J (2006). Visualization of the cortical dopamine transporter in type 1 and 2 alcoholics with human whole hemisphere autoradiography. Eur Neuropsychopharmacol 16: 552-560.

Tupala E, Kuikka JT, Hall H, Bergstrom K, Sarkioja T, Rasanen P et al. (2001). Measurement of the striatal dopamine transporter density and heterogeneity in type 1 alcoholics using human whole hemisphere autoradiography. Neuroimage 14: 87-94.

Tupala E, Tiihonen J (2004). Dopamine and alcoholism: neurobiological basis of ethanol abuse. Prog Neuropsychopharmacol Biol Psychiatry 28: 1221-1247.

van Dyck C, Malison R, Seibyl J, Laruelle M, Klumpp H, Zoghbi S et al. (2000). Age-related decline in central serotonin transporter availability with $\left[{ }^{1231}\right] \beta$-CIT SPECT. Neurobiol Aging 21: 497-501.

Vengeliene V, Bilbao A, Molander A, Spanagel R (2008). Neuropharmacology of alcohol addiction. Br J Pharmacol 154: 299-315.

Volkow ND, Wang GJ, Fowler JS, Logan J, Hitzemann R, Ding YS et al. (1996). Decreases in dopamine receptors but not in dopamine transporters in alcoholics. Alcohol Clin Exp Res 20: 1594-1598.

von Knorring AL, Bohman M, von Knorring L, Oreland L (1985). Platelet MAO activity as a biological marker in subgroups of alcoholism. Acta Psychiatr Scand 72: 51-58.

Von Knorring L, Oreland L (1985). Personality traits and platelet monoamine oxidase in tobacco smokers. Psychol Med 15: 327-334.

von Knorring L, Oreland L, von Knorring AL (1987). Personality traits and platelet MAO activity in alcohol and drug abusing teenage boys. Acta Psychiatr Scand 75: 307-314.

Windham G, Elkin E, Swan S, Waller K, Fenster L (1999). Cigarette smoking and effects on menstrual function. Obstet Gynecol 93: 59-65. 